\title{
Electrochemical Characterization and HOMO-LUMO Studies on Fabricated PVB/Graphite and PVB/GO Nanocomposites
}

\author{
Harish Mudila, ${ }^{a, b}$ Parteek Prasher, ${ }^{c}$ Himanshu Kapoor, ${ }^{b}$ \\ Sweta $\operatorname{Rana}^{a}$ and M.G.H. Zaidi ${ }^{a, *}$ \\ ${ }^{a}$ Department of Chemistry, G. B. Pant University of Agriculture and Technology, \\ Pantnagar, Uttarakhand, India-263145 \\ ${ }^{b}$ Department of Chemistry, Lovely Professional University, \\ Phagwara, Punjab, India-144411 \\ ${ }^{c}$ Department of Chemistry, UPES, Dehradun, Uttarakhand, India-248007
}

Received September 13, 2017; accepted January 18, 2018

\begin{abstract}
Carbonaceous materials are used to generate composites for numerous purposes, due to their extraordinary properties. In this context, we have carried out a study on the modified properties, viz. thermal stability and specific capacitance of the composites fabricated by the introduction of a carbonaceous material (graphite and graphene oxide) into the Polyvinyl Butyral matrix. Since it has excellent adhesibility and dielectric permittivity, and it can be employed as an electrode in sensors, polyvinyl butyral is used in the current investigation, along with carbonaceous materials, for electrochemical and bandgap properties (HOMO-LUMO) studies. Spectroscopic FT-IR, XRD and SEM analyses remark the comprehensive entanglement of the two components. Various fabricated composites show an increased thermal stability, with a percentage of carbonaceous filler, as suggested by TGA. Cyclic voltammetry studies reveal that PVB acts as an excellent binder, and as a good matrix for the charge movement through it, because it has a good level of dielectric permittivity, thus enabling fabricated materials to be developed as good candidates for supercapacitive batteries.
\end{abstract}

Keywords: Polyvinyl butyral, graphene oxide, graphite, cyclic voltammetry, HOMOLUMO, supercapacitance.

\section{Introduction}

Carbon based polymer composites, due to their extremely versatile nature, have always been an attraction epicenter in the fabrication of composites/nanocomposites, for innumerable engineering and research applications. The addition of carbonaceous fillers to a polymer matrix engenders

\footnotetext{
*Corresponding author. E-mail address: harismudila@gmail.com
} 
a remarkable feature to the composites. The properties and nature of carbon based composites count on the components selection (matrix and reinforced material), and the way as they are managed. Their features, viz. light weight, extraordinary stiffness and fatigue holding, corrosion resistance, thermal, energy expansion and durability properties, make carbonaceous materials perfect candidates for manufacturing a polymeric composite [1-3]. Investigators have been using various carbon based composites, viz. polymer/CNT [4-7], polymer/graphite [8-11], polymer/graphene [12-15], polymer/GO (graphene oxide or graphite oxide) [14, 16-20], among others, because of their various mechanical, electrical, optical, rheological, gas barrier, etc., properties. In parallel, a range of synthetic polymers has also been used for obtaining numerous desired properties. In this regard, graphite $(\mathrm{G})$ and graphene oxide $(\mathrm{GO})$ are vastly used in fillers in the field of composite/nanocomposites. The unique properties [21-25] of the mentioned added fillers have introduced marked enhanced physical, mechanical and antimicrobial properties. However, the utmost challenge in this field is the uniform dispersion of the filler in the polymer matrix, due to the strong interlayer cohesive energy and surface inertia [26], for which numerous synthetic modifications, viz. melt-spinning, electro-spinning, etc., are employed [27]. The preparation of a graphite and graphene oxide based composite with various polymers, viz. nylon 6 [28] and epoxy [29], has been reported in this context, since it provides better entanglement of the fillers with the polymeric matrix.

In this itinerary to achieve thermally and electrochemically improved polymerfiller nanocomposites, in our present work we have carried out the ultrasonicated fabrication of a nanocomposite of graphite $(\mathrm{G})$ and graphene oxide $(\mathrm{GO})$, based on polyvinyl butyral (PVB). PVB has various applications, such as for laminated safety glass and adhesive materials, due to its various components, such as vinyl butyral, vinyl alcohol, and vinyl acetate, which bestow numerous physical characteristics, for instance, good processability, durability, elasticity and compatibility with certain polymers, fillers, plasticizers, etc. [30]. PVB is frequently employed in the fabrication of membrane matrices for immunosensors and electrodes; it possesses a controllable morphology, and it is economic and easily accessible [27]. Apart from the above characteristics, PVB is found to have relatively higher polarity (as compared to some other vinyl polymers, viz. PVC, etc. [27]), low electrical conductivity [31-32] and good dielectric permittivity [33].

Earlier reports presented by Hajian et al. [26] on PVB-graphene composites have led the researchers to work in this direction, to study the various chemical, thermal and electrochemical properties of the synthesized composites. The introduction of fillers (G/GO) showed a marked difference in the composite's properties, as equated to the sole polymer. In the present investigation, the preparation of a composite system based on PVB and graphite/GO has been attempted, by applying a procedure involving the dispersion of carbonaceous fillers in the polymer matrix, with the assistance of a probe ultrasonicator. This ultrasonication process renders a comprehensive homogenization of the filler in the PVB matrix, which was ascertained through FT-IR, XRD and SEM 
techniques. The thermal and electrochemical studies suggested the thermal, charge conduction and electrochemical stability of the fabricated materials.

\section{Experimental}

\section{Materials}

Nano sized graphite (particle size $\sim 60$ mesh) and N-Methyl pyrollidone were purchased from Loba Chemie. Polyvinyl Butyral (PVB, $\left.\mathrm{M}_{\mathrm{w}}=30500\right)$ was obtained from Himedia, while GO was prepared through modified Hummers process [32].

\section{Preparation of composite materials}

PVB (200 mg dissolved into $1 \mathrm{~mL}$ of NMP) matrix acts as a binder for the electroactive material (graphite and GO). The above composition was ultrasonicated by a probe ultrasonicator (QS4, $700 \mathrm{~W}, 20 \mathrm{kHz}$ ) at room temperature, until a clear homogenized solution/mixture was obtained. To this homogeneous mixture of graphite and GO, PVB, in a varying ratio $(1: 1,2: 1$ and 1:2), was separately added, and again sonicated for $1 / 2 \mathrm{~h}$, until the filler was thoroughly mixed in the above mentioned matrix. Table 1 demonstrates the respective ratios for the fabricated materials.

Table 1. Respective quantitative values and specific capacitances of the samples.

\begin{tabular}{lcccc}
\hline $\begin{array}{l}\text { Sample } \\
\text { code }\end{array}$ & $\begin{array}{c}\text { PVB } \\
(\mathbf{g})\end{array}$ & $\begin{array}{c}\text { Graphite } \\
(\mathbf{g})\end{array}$ & $\begin{array}{c}\text { GO } \\
(\mathbf{g})\end{array}$ & $\begin{array}{c}\text { Cs } \\
(\mathbf{F} / \mathbf{g})\end{array}$ \\
\hline PVB & 0.2 & - & - & 18 \\
PG-I & 0.2 & 0.1 & - & 65 \\
PG-II & 0.2 & 0.2 & - & 130 \\
PG-III & 0.2 & 0.4 & - & 202 \\
PGO-I & 0.2 & - & 0.1 & 43 \\
PGO-II & 0.2 & - & 0.2 & 92 \\
PGO-III & 0.2 & - & 0.4 & 144 \\
\hline
\end{tabular}
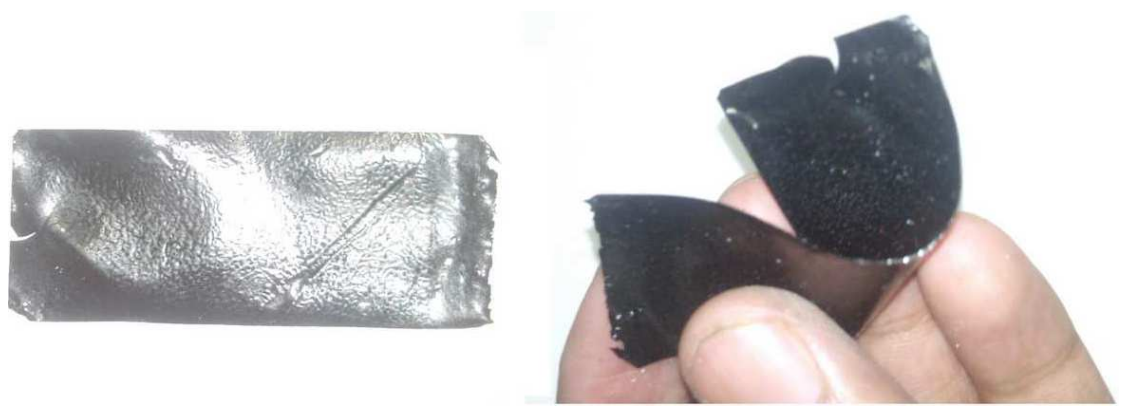

Figure 1. Fabricated flexible film.

\section{Electrode preparation}

PVB acts as an excellent binder, readily dissolved/homogenized in acetone, chloroform, DMF and NMP. The composite solution was spread over a mould, to give a very good thin flexible film (Fig. 1), when dried in air for 24 hours, followed by drying in a vacuum oven (NSW-251, India) at $100 \pm 1{ }^{\circ} \mathrm{C}$ for $48 \mathrm{~h}$, and it has been used to study spectro-chemical, thermal, and electrochemical 
properties. The composite prepared by the above method was applied on 316stainless steel $(1 \mathrm{~cm} \times 1 \mathrm{~cm})$, for testing its electroactive behavior. The applied material on the electrode, in each case, was found to have the active mass of $0.5 \pm 0.1 \mathrm{~g}$.

\section{Characterization}

\section{Scanning electron microscope}

SEM images of the PVB, PVB/G, and PVB/GO composites were observed by JEOL (JSM-6610 LV), with a beam voltage of $5 \mathrm{kV}$, at a magnification of 250x $(100 \mu \mathrm{m})$ and 500x $(50 \mu \mathrm{m})$.

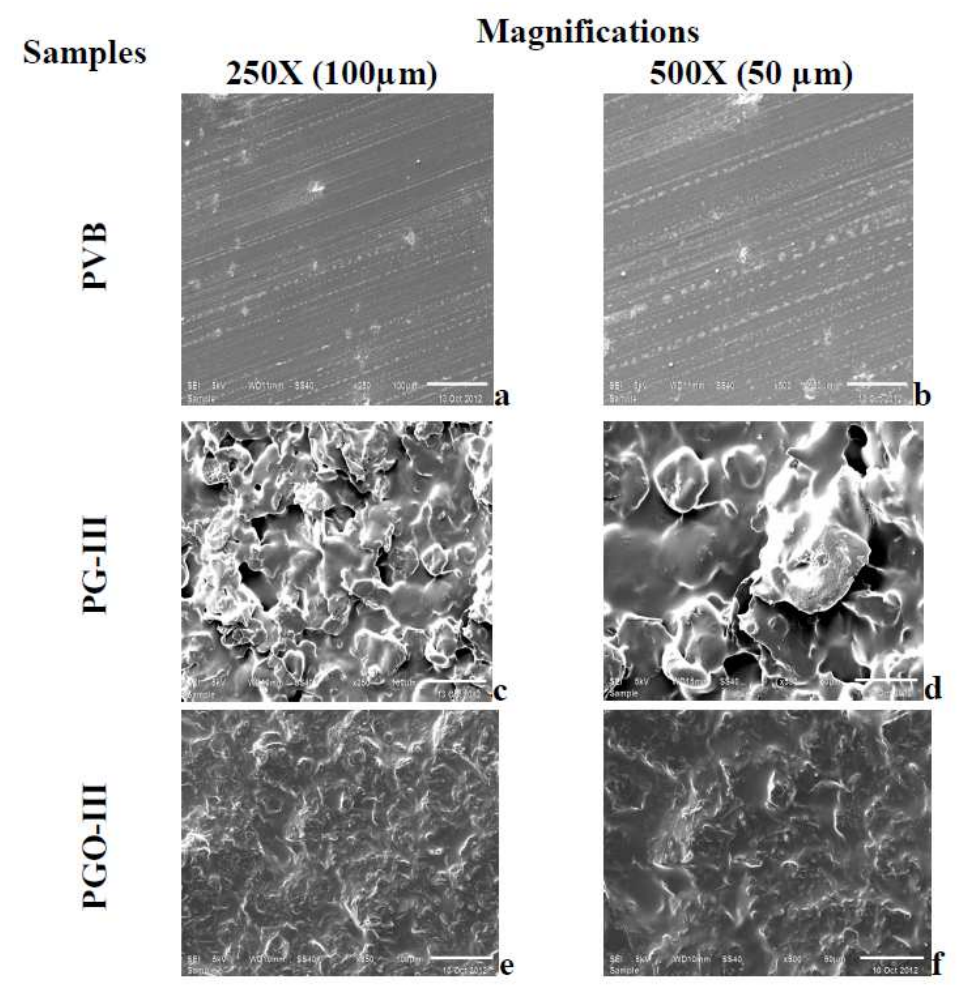

Figure 2. (a-b) SEM images of PVB, (c-d) respective representatives of PG and (e-f) PGO.

The PVB matrix on the substrate reveals a uniform and continuous surface at both the magnifications (Fig. 2a and b). On adding filler to the matrix, i.e., in the nanocomposites case, it was observed a homogenous distribution of graphite and GO in the matrix. In the graphite case, a nanoflower [33] like structure was observed, which depicts that there is not any chemical interaction among the two interfaces (Fig. 2c and d), while in the case of PVB-GO composites, no such arrangement was observed, which also may be because of the weak intermolecular bonding (Fig. 2e and f).

\section{FTIR}

FT-IR of all the pure and composite materials are shown in Fig. 3(a) and (b). 


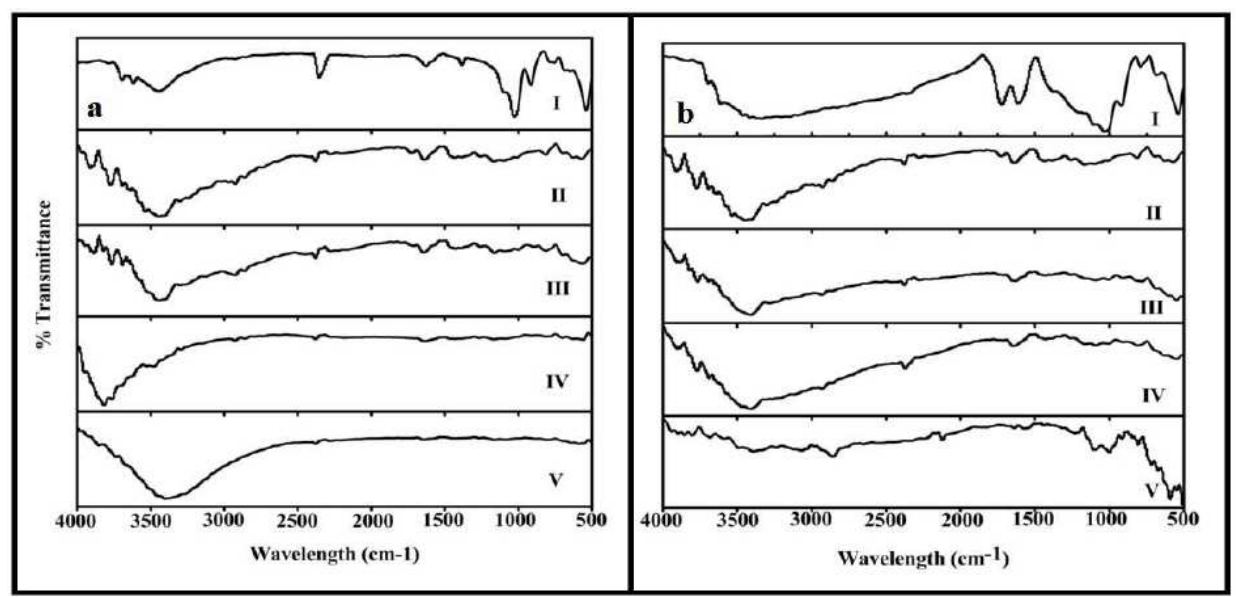

Figure 3. FTIR spectrum of (a) Graphite (I), PVB (II) and their composites (III-V), and (b) GO (I), PVB (II) and their composites (III-V).

All figures are in positive agreement with the results explained by previous researchers. The peak at $3450 \mathrm{~cm}^{-1}$ is for the $-\mathrm{OH}$ group of PVB (Fig. 3a and b (II)). The broad band shape of this peak indicates a certain extent of hydrogen bonding between the $\mathrm{O}-\mathrm{H}$ moieties within the polymer chains [34]. Symmetric and asymmetric $\mathrm{C}-\mathrm{H}$ bond stretch bands are observed in the range of 2800 to $3000 \mathrm{~cm}^{-1}$. The peak at $1000 \mathrm{~cm}^{-1}$ can be attributed to the $\mathrm{C}-\mathrm{OH}$ stretching vibration of PVB. The peaks at $1150 \mathrm{~cm}^{-1}$ principally correspond to the $\mathrm{C}-\mathrm{O}-\mathrm{C}$ backbone, while those in the range of 1250 to $1735 \mathrm{~cm}^{-1}$ are due to $\mathrm{C}=\mathrm{O}$ vibrations, and to the alcoholic O-H deformation modes of PVB [35]. Graphite has revealed characteristic absorptions $\left(\mathrm{cm}^{-1}\right)$ at $3447(\mathrm{v} \mathrm{O}-\mathrm{H})$ and $1628.79(\delta$ $\mathrm{O}-\mathrm{H}$ ) (which are due to the presence of an absorbed moisture (Fig. 3a (I))) and characteristic absorptions at $\sim 3333(\mathrm{v} \mathrm{O}-\mathrm{H}), 1723$ (v COOH), 1613 (remaining $\mathrm{sp}^{2}$ character), 1378 (v C-O-C), 1221.20 (C-O for oxirane), and $1033 \mathrm{~cm}^{-1}$ ( $\mathrm{v}-$ $\mathrm{C}-\mathrm{OH}$ ), which indicate the conversion of graphite into GO (Fig. 3b (I)) [32]. The representatives of $\mathrm{PVB} / \mathrm{G}$ composites reveal all the characteristic absorption peaks of PVB and graphite, with an increasing percentage of filler in the composites. The higher amount of graphite increases the peak intensity near to $3450 \mathrm{~cm}^{-1}$ (Fig. 3a. (III-V)). Similar results were observed in the case of PVB/GO nanocomposites (Fig. 3b (III-V)).

\section{$X R D$}

XRD analyses of PVB, PVB/G and PVB/GO are shown in Fig. 4. No crystalline peak is observed in the case of PVB, due to its amorphous nature (Fig. $4 \mathrm{a}$ and $4 \mathrm{~b}$ (II)). PVB shows $2 \theta=23.26^{\circ}$ and gallery spacing (d) of $3.82 \AA$. The peak corresponding to $2 \theta=26.43^{\circ}$, with gallery spacing $(\AA)$ of $\mathrm{d}=3.369$, shows the usual peaks of graphite. In the case of $\mathrm{GO}$, a reduction in the $2 \theta=11.83^{\circ}$, with gallery spacing of $7.473 \AA$, has been observed, which indicates the flaking of graphite into GO [32]. On the addition of graphite to the matrix, a clear peak corresponding to graphite is observed, along with a non-crystalline peak corresponding to PVB. Likewise, on the addition of GO to the matrix, it is perceived that the crystallinity of the composite is fairly increased. 


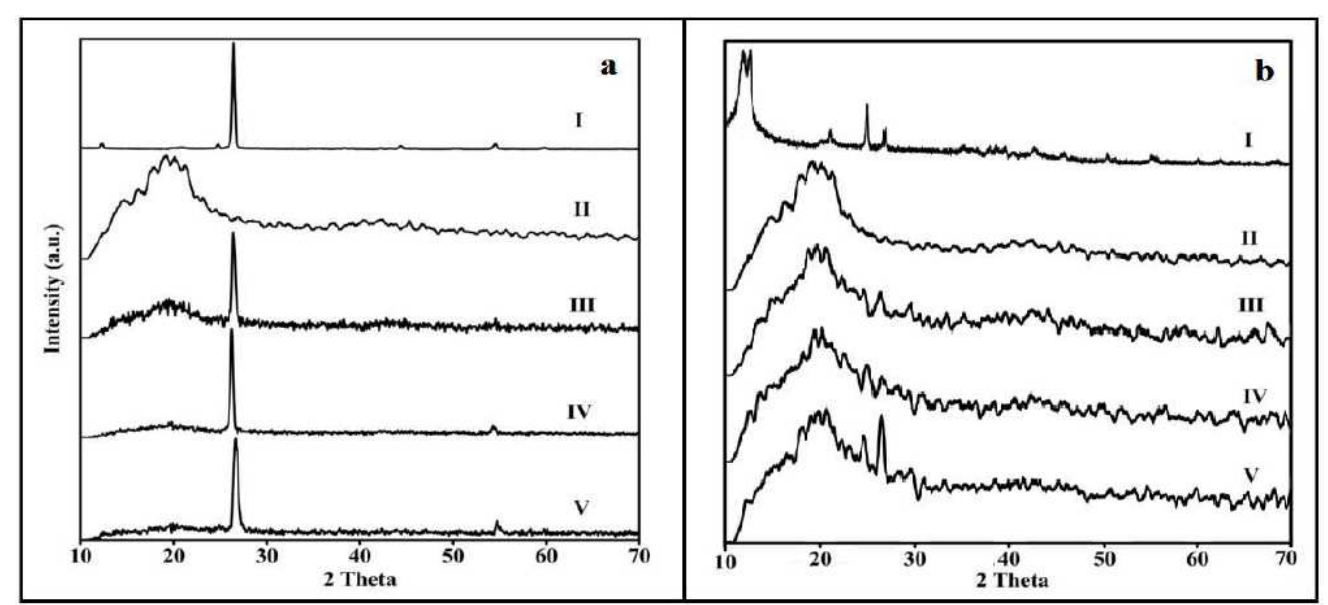

Figure 4. XRD of (a) graphite (I), PVB (II) and their composites (III-V), and (b) GO (I), PVB (II) and their composites (III-V).

\section{Thermogravimetric analysis (TGA)}

Thermal properties, viz. thermal stability, were ascertained through thermogravimetric analysis of the polymer and the other nanocomposites (Fig. 5a and b). The study was carried under $\mathrm{N}_{2}$ atmosphere, with a flow rate of 30 $\mathrm{mL} / \mathrm{min}$, using a Thermogravimetric analyzer (TGA-50/50H, Shimadzu). The samples were heated at room temperature to $600{ }^{\circ} \mathrm{C}$, with an increase of 5 ${ }^{\circ} \mathrm{C} / \mathrm{min}^{-1}$. In the graphite case (Fig. 5a I), no observable difference in the mass was observed at the end of the process [36]. The TGA analysis of the PVB displayed in Fig. 5a II depicted the stability of the matrix, up to a temperature of $\sim 300{ }^{\circ} \mathrm{C}$. Beyond this temperature, a steep loss in the mass occurred, related to PVB decomposition and degradation [35]. Above $350{ }^{\circ} \mathrm{C}$, initially, butanal and butenal were decomposed by the elimination of butyral groups. Above $400{ }^{\circ} \mathrm{C}$, there was elimination of acetic acid as a trifling component, by the acetate group removal.
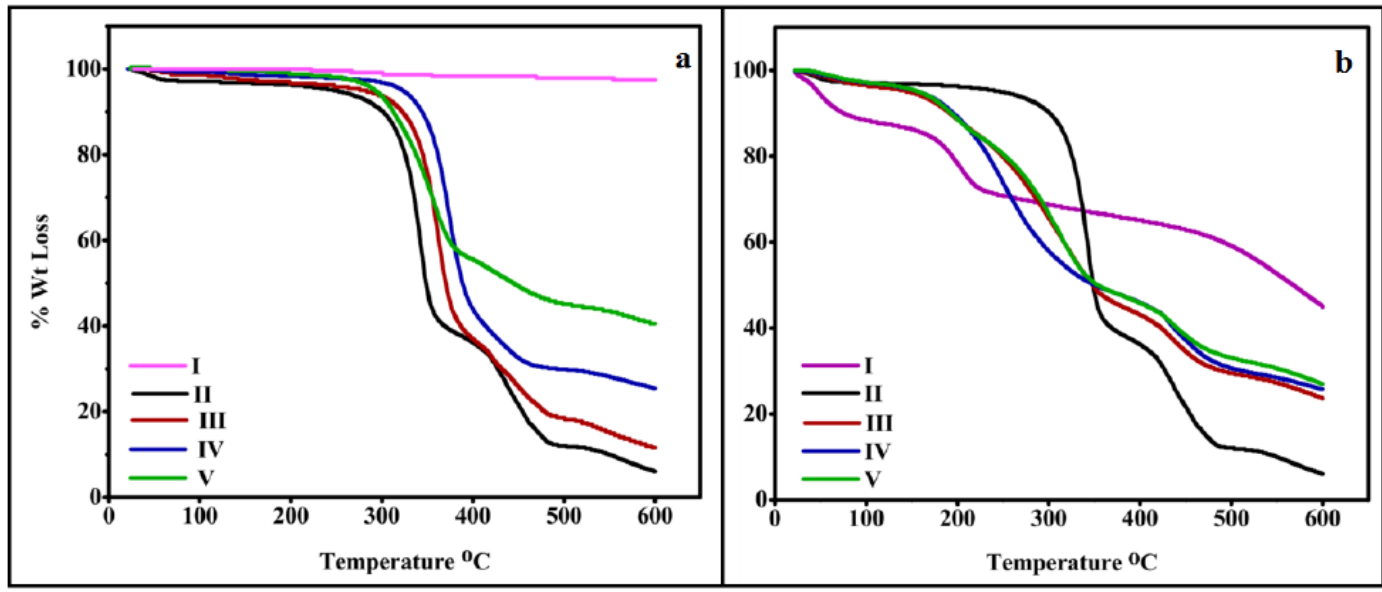

Figure 5. TGA of (a) graphite (I), PVB (II) and their composites (III-V), and (b) GO (I), PVB (II) and their composites (III-V).

The fillers effect was found to be pronounced with their increasing amounts. It was observed, in graphite and GO cases, that, with an increase in the individual 
filler ratio, in both matrices, the thermal stability was enhanced, which was more pronounced in the graphite case, as compared to GO. This attests for the graphite capability to endure a wider temperature range, as compared to GO, which indicates a low thermal stability with the continuous supply of decomposed oxidized products $\left(\mathrm{CO}_{2}, \mathrm{CO}\right)$, in a given temperature range [36-37].

\section{Electrochemical analysis}

Electrochemical properties of all the materials were analyzed via Cyclic Voltammetry (CV). The materials displayed close agreement with $\mathrm{CV}$ guidelines. All scans were made in a $1 \mathrm{M} \mathrm{KOH}$ electrolyte, which is considered as the better electrolyte for ions mobility [38]. PVB coated SS electrode shows the least amount of electroactivity, at the scan rates of $0.1 \mathrm{~V} / \mathrm{s}$. Among all the materials, it was observed that the peaks disappeared, showing that the electron transfer was restricted, due to the insulating property of the PVB film [27].

However, Lian et al. perceived a minute current peak, accredited to the conversion of PVB hydroxyls to aldehydes, through electrolytic oxidation [39]. Meanwhile, graphite shows a good level of redox behavior, as compared to GO and PVB, at the sweep rate of $0.1 \mathrm{~V} / \mathrm{s}$ (Fig. 6). Good specific conductance suggested by graphite's CV indicates its appreciable high surface area.

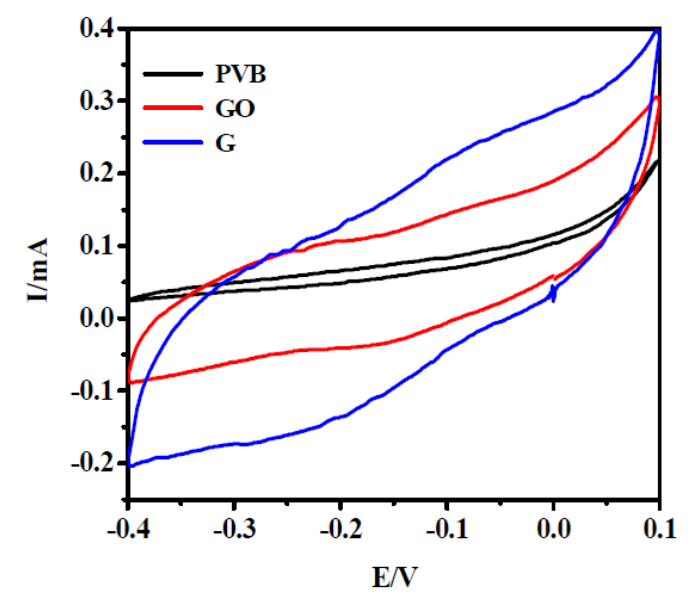

Figure 6. CV of PVB, graphene oxide (GO) and graphite (G).

$\mathrm{CV}$ scans for both types of composite materials, at varying concentration ratios, were taken at the scan rate of $0.1 \mathrm{~V} / \mathrm{s}$, in the potential window of -0.4 to $0.1 \mathrm{~V}$. All the concentrations show cyclic scans at the given potential range (Fig. 7). 

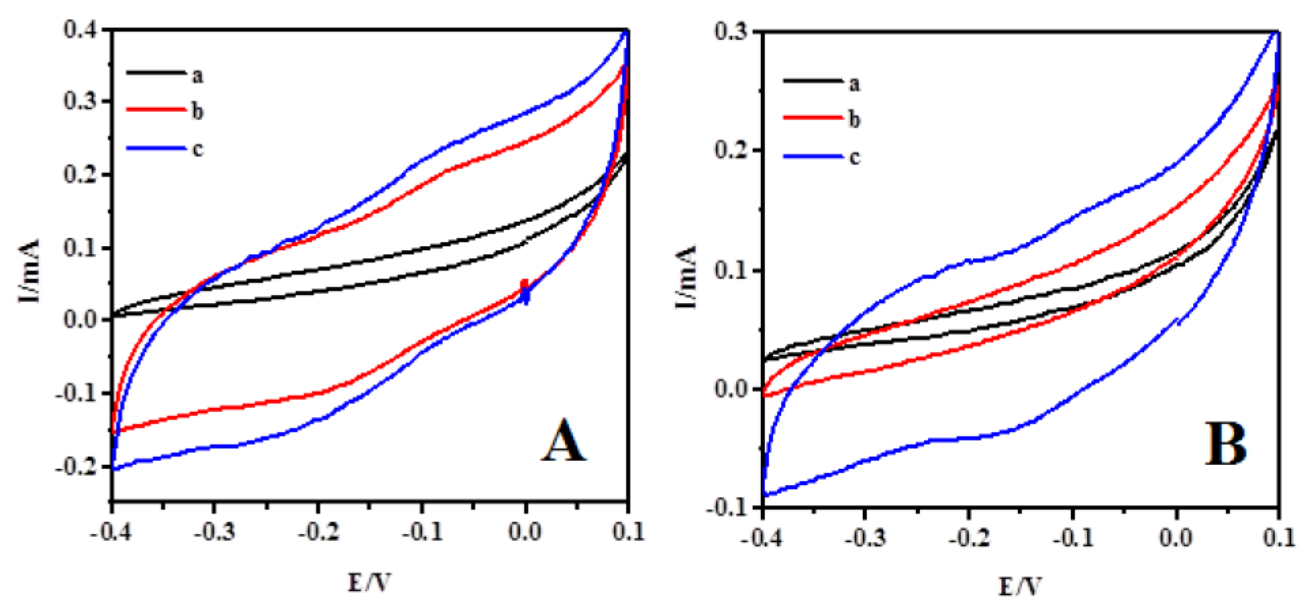

Figure 7. CV of (A) PVB: graphite and (B) PVB:GO, at varying fillers concentrations.

When the proportion of electroactive material in the PVB matrix was raised (filler: PVB, 1:2, 1:1, 2:1), it was observed that the specific capacitance for the composites was also amplified. In the PVB/GO composites case, the specific capacitance ranged between $43 \mathrm{~F} / \mathrm{g}$ to $144 \mathrm{~F} / \mathrm{g}$, while in the $\mathrm{PVB} / \mathrm{G}$ case, the range of specific capacitance was of $65 \mathrm{~F} / \mathrm{g}$ to $202 \mathrm{~F} / \mathrm{g}$, for the three variants. The specific capacitance was determined to be the lowest, in the pure PVB $12 \mathrm{~F} / \mathrm{g}$ case, and it was calculated according to the following relation [38]:

$$
\operatorname{cs}(\mathrm{F} / \mathrm{g})=\frac{q a+|q c|}{2 m \Delta V}
$$

The cyclability of the fabricated electrode material (filler: PVB, 2:1) was done for 500 repeated cycles in a $1 \mathrm{M} \mathrm{KOH}$ solution, at a sweep rate of $0.1 \mathrm{~V} / \mathrm{s}$, in the voltage window of -0.4 to $0.1 \mathrm{~V}$. The results show that the repeated cycles had a very low effect on the binding capacity of the binder with the SS electrode (98.51 and $95.83 \%$ retention, in the G/PVB and GO/PVB cases, respectively), thus suggesting PVB applicability as an excellent binder, as also suggested by previous studies (Fig. 8).

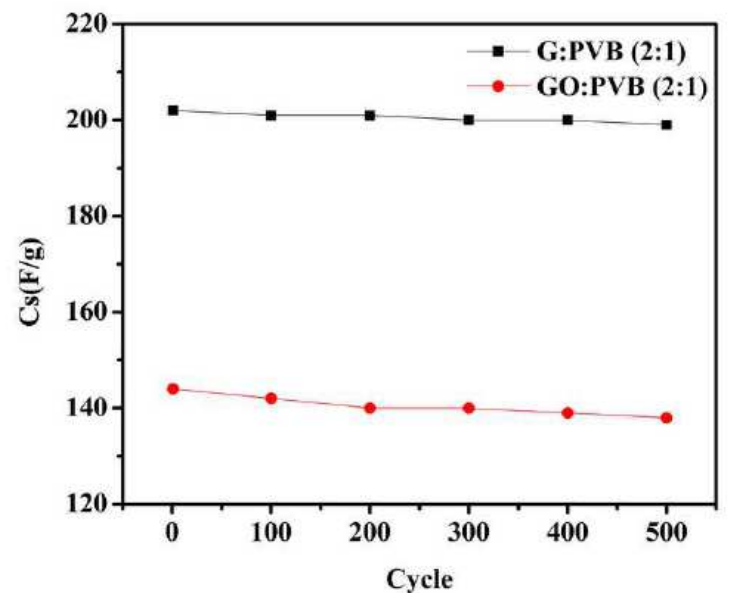

Figure 8. Effect of cycle numbers on the electrode stability. 


\section{Energy gap studies}

$\mathrm{CV}$ is an expedient technique to evaluate the energy band gap of organic materials. For an organic material, highest occupied molecular orbital (HOMO) and lowest unoccupied molecular orbital (LUMO) correspondingly symbolized the oxidation and reduction processes. The redox potentials ( $E_{\text {red }}$ and $E_{\text {oxi }}$ ) (Fig. 9) designate those two procedures [40]. Ferrocene was employed as a reference to determine HOMO and LUMO energy levels. Oxidation and reduction of all compounds were measured under the same experimental conditions, to estimate both HOMO and LUMO energies. The CV curve shows the band gap to be 0.25 $\mathrm{eV}$ and $0.39 \mathrm{eV}$ for $\mathrm{PVB} / \mathrm{GO}$ and $\mathrm{PVB} /$ graphite, respectively, at a sweep rate of $0.1 \mathrm{~V}$. The determinations were done with the relation [41]:

$$
\begin{array}{r}
\mathrm{E}_{\mathrm{LUMO}}=\left[\left(\mathrm{E}_{\text {red }}{ }^{*} \mathrm{E}_{1 / 2 \text { (ferrocene) })}\right)+4.8\right] \mathrm{eV} \\
\mathrm{E}_{\text {HOMO }}=\left[\left(\mathrm{E}_{\mathrm{ox}^{-}} * \mathrm{E}_{1 / 2 \text { (ferrocene) })}\right)+4.8\right] \mathrm{eV} \\
* \mathrm{E}_{1 / 2 \text { (ferrocene) }}=0.41 \mathrm{~V}
\end{array}
$$

Figure 9. $\mathrm{E}_{\mathrm{oxi}}$ and $\mathrm{E}_{\text {red }}$ onsets for (a) GO and (b) graphite.

\section{Conclusion}

In conclusion, thermally stable and electrochemically active composites, at varying concentrations of graphite and graphene oxide to PVB, were fabricated via a simple untrasonication process, for the production of cost effective and high current delivering energy storage devices. Results demonstrate that, with increasing percentages of filler in the polymer matrix, the above mentioned properties were also amplified. The fabrication of composites was ascertained through various spectroscopic techniques, viz. FT-IR, XRD and SEM, which validate complete entanglement of the two components in each variant. Records extracted from cyclic voltammetry determine that the fabricated material composites (more specifically, containing graphite) could be used as better candidates for establishing a supercapacitive material, with PVB acting as an exceptional binder material.

\section{References}

1. Corb I, Manea F, Radovan C, et al. Sensors. 2007;7:2626.

2. Zhang W, Dehghani-Sanij AA, Blackburn RS. J Mat Sci. 2007;42:3408.

3. Wang Q, Han XH, Sommers A, et al. Int J Refrigeration. 2012;35:7.

4. Peng H. J Am Chem Soc. 2008;130:42.

5. Song K, Zhang Y, Meng J, et al. Materials.2013;6:2543.

6. Spitalsky Z, Tasis D, Papagelis K, et al. Prog Polym Sci. 2010;35:357.

7. Yang YK, China PR, Xie XL, et al. Polym-Carbon Nanotube Composites. 2011:55.

8. Chen G, Wu C, Weng W, et al. Polymer. 2003;44:1781.

9. Li N, Wang K, Zhang Q, et al. Polym Composites. 2014;35:1943. 
10. Calixto MCF, Mendes RK, Oliveira AC, et al. Mater Res. 2007;10:109.

11. Nasir A, Kausar A, Younus A. Polym-Plast Technol Eng. 2015;54:750.

12. Achaby ME, Arrakhiz FE, Vaudreuil S, et al. Polym Composites. 2012;33:733.

13. Miculescu M, Thakur VK, Miculescu F, et al. Polym Adv Technol. 2016;27:844.

14. Khan ZU, Kausar A, Ullah H, et al. J Plastic Film Sheeting. 2016;32:336.

15. Tjong SC. J Nanosci Nanotechnol. 2014;14:1154.

16. Yuan B, Bao C, Song L, et al. Chem Eng J. 2014;237:411.

17. Tien CP, Teng H. J Power Sources. 2010;195:2414.

18. Mahendran R, Sridharan D, Santhakumar K, et al. J Nanosci. 2016:1.

19. Higginbotham AL, Lomeda JR, Morgan AB. ACS Appl Mater Interf. 2009;1:2256.

20. Tzeng P, Stevens B, Devlaming I, et al. Langmuir, 2015;31:5919.

21. Hansora DP, Shimpi NG, Mishra S. Minerals, Metals \& Mater Soc. 2015;67:2855.

22. Bannov AG, Timofeeva AA, Shinkarev VV, et al. Prot Metals Phys Chem Surf. 2014;50:183.

23. Liu S, Zeng TH, Hofmann M, et al. ACS Nano. 2011;5:6971.

24. Srivastava SK, Pionteck J. J Nanosci Nanotechnol. 2015;15:1984.

25. Sengupta R, Bhattacharya M, Bandyopadhyay S, et al. Prog Polym Sci. 2011;36:638.

26. Hajian M, Reisi MR, Koohmareh GA. J Polym Res. 2012;19:9966.

27. Wang L, Xu L. J Agric Food Chem. 2014;62:10248.

28. Weng W, Chen G, Wu D, et al. J. of Polymer Science Part B: Polymer Physics. 2004;42(15):2844.

29. Miller SG, Bauer JL, Maryanski MJ, et al. Composites Sci Technol. 2010;70:1120.

30. Sonego M, Costa LC, Ambrosio JD. Polímeros. 2015;25:175.

31. Li Y, Yu T, Pui T, et al. Composites Sci Technol. 2011;71:1665.

32. Mudila H, Zaidi MGH, Rana S, et al. Int J Chem Analyt Sci. 2013;4:139.

33. Kim MY, Choi SW, Boo SJ, et al. J Nanosci Nanotechnol. 2015;15:8055.

34. Fernandez MD, Fernandez MJ, Hoces P. J Appl Polym Sci. 2006;102:5007.

35. Ambrosio JD, Lucas AA, Otaguro H. Polym Composites. 2011;32:776.

36. Naebe M, Wang J, Amini A, et al. Sci Rep. 2014;4:4375.

37. Mudila H, Joshi V, Rana S, et al. Carbon Lett. 2014;15:171.

38. Mudila H, Zaidi MGH, Rana S, et al. Carbon Lett. 2016;18:43.

39. Lian F, Wen Y, Ren Y, et al. J Memb Sci. 2014;456:42.

40. Leonat L, Sbarcea G, Branzoi IV. UPB Sci Bull, Ser B. 2013;75:111.

41. Shafiee A, Salleh MM, Yahaya M. Sains Malaysiana. 2011;40:173. 